\title{
Quantification of FDG-PET/CT with delayed imaging in patients with newly diagnosed recurrent breast cancer
}

\author{
Christina Baun ${ }^{1 *}$, Kirsten Falch ${ }^{1}$, Oke Gerke ${ }^{1,2}$, Jeanette Hansen ${ }^{1}$, Tram Nguyen ${ }^{1}$, Abass Alavi $^{3}$, \\ Poul-Flemming Høilund-Carlsen ${ }^{1}$ and Malene G. Hildebrandt ${ }^{1}$
}

\begin{abstract}
Background: Several studies have shown the advantage of delayed-time-point imaging with 18F-FDG-PET/CT to distinguish malignant from benign uptake. This may be relevant in cancer diseases with low metabolism, such as

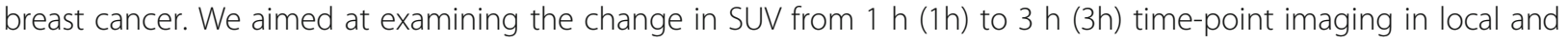
distant lesions in patients with recurrent breast cancer. Furthermore, we investigated the effect of partial volume correction in the different types of metastases, using semi-automatic quantitative software (ROVER $\left.{ }^{T M}\right)$.

Methods: One-hundred and two patients with suspected breast cancer recurrence underwent whole-body PET/CT scans $1 \mathrm{~h}$ and $3 \mathrm{~h}$ after FDG injection. Semi-quantitative standardised uptake values (SUVmax, SUVmean) and partial volume corrected SUVmean (cSUVmean), were estimated in malignant lesions, and as reference in healthy liver tissue. The change in quantitative measures from $1 \mathrm{~h}$ to $3 \mathrm{~h}$ was calculated, and SUVmean was compared to cSUVmean. Metastases were verified by biopsy.
\end{abstract}

Results: Of the 102 included patients, 41 had verified recurrent disease with in median 15 lesions (range 1-70) amounting to a total of 337 malignant lesions included in the analysis. SUVmax of malignant lesions increased from $6.4 \pm 3.4$ [0.9-19.7] (mean \pm SD, min and max) at $1 \mathrm{~h}$ to $8.1 \pm 4.4[0.7-29.7]$ at $3 \mathrm{~h}$. SUVmax in breast, lung, lymph node and bone lesions increased significantly $(p<0.0001)$ between $1 \mathrm{~h}$ and $3 \mathrm{~h}$ by on average $25,40,33$, and $27 \%$, respectively. A similar pattern was observed with (uncorrected) SUVmean. Partial volume correction increased SUVmean significantly, by 63 and $71 \%$ at $1 \mathrm{~h}$ and $3 \mathrm{~h}$ imaging, respectively. The highest impact was in breast lesions at 3h, where cSUVmean increased by $87 \%$ compared to SUVmean.

Conclusion: SUVs increased from $1 \mathrm{~h}$ to $3 \mathrm{~h}$ in malignant lesions, SUVs of distant recurrence were in general about twice as high as those of local recurrence. Partial volume correction caused significant increases in these values. However, it is questionable, if these relatively modest quantitative advances of $3 \mathrm{~h}$ imaging are sufficient to warrant delayed imaging in this patient group.

Trial registration: ClinicalTrails.gov NCT01552655. Registered 28 February 2012, partly retrospectively registered. Keywords: FDG-PET/CT, Breast cancer, Delayed-time-point, Standardised uptake values, Partial volume correction

\footnotetext{
* Correspondence: Christina.baun@rsyd.dk

'Department of Nuclear Medicine, University Hospital, Sdr. Boulevard 29,

5000 Odense C, Denmark

Full list of author information is available at the end of the article
}

(c) The Author(s). 2018 Open Access This article is distributed under the terms of the Creative Commons Attribution 4.0 International License (http://creativecommons.org/licenses/by/4.0/), which permits unrestricted use, distribution, and reproduction in any medium, provided you give appropriate credit to the original author(s) and the source, provide a link to the Creative Commons license, and indicate if changes were made. The Creative Commons Public Domain Dedication waiver (http://creativecommons.org/publicdomain/zero/1.0/) applies to the data made available in this article, unless otherwise stated. 


\section{Background}

Breast cancer is the most frequent cancer among women in western countries, and up to $30 \%$ of patients are likely to develop recurrence [1, 2]. 18F-fluoro-deoxy-glucose positron emission tomography/computed tomography (FDG-PET/CT) is useful in the diagnosis, staging and therapeutic follow-up of patients with recurrent breast cancer, and is especially better than conventional imaging at detecting distant metastases [3-5].

FDG is not specific for malignancy; however, recent studies have shown the advantage of delayed or dualtime imaging with FDG-PET to distinguish malignant from benign uptake [6-8]. The underlying rationale is that malignant cells have more glucose transporters and hexokinases and less glucose-6-phosphatase (G6Pase), which leads to FDG accumulation over time compared to benign cells $[9,10]$. Delayed scan time-points may thus improve the image quality due the greater difference between tumour and background levels [11-14]. This may be relevant in cancer diseases with low metabolism, such as breast cancer.

Only a few studies have examined the use of delayed time-point imaging (DTPI) in whole-body FDG-PET/CT to show the FDG accumulation over time associated with distant metastases [15-17]. The literature suggests that more prospective studies are needed to provide a better understanding of the use of DTPI in detecting recurrent breast cancer $[6,18,19]$. Analysis of PET data is often performed semi-quantitatively by measuring standardised uptake values (SUV) in lesions suspected of malignancy [20-22]. SUV has been referred to correlate well with histological and biological tumour characteristics, and can be an important tool in the diagnostic report for breast cancer patients [23-25]. SUV is strongly affected by the partial volume effect (PVE), however, which can cause a significant underestimation of the lesion uptake level [26-28]. Although methods for partial volume correction (PVC) have been developed to overcome this limitation, no method has yet found its place in daily clinical practice. Further evidence is needed to state the usefulness and feasibility of these software methods [29-32].

We aimed at examining the value of whole-body FDG$\mathrm{PET} / \mathrm{CT}$ performed at $3 \mathrm{~h}(3 \mathrm{~h})$ compared to the standard imaging time-point at $1 \mathrm{~h}(1 \mathrm{~h})$, in patients suspected of recurrent breast cancer, using quantitative software that included PVC.

Our objectives were to investigate i) the change in standardised uptake values from early $(1 \mathrm{~h})$ to delayed (3h) time-point imaging in local and distant lesions, by measuring SUVmax, SUVmean and correcting SUVmean for PVE (cSUVmean), and ii) the effect of PVC by comparing SUVmean and cSUVmean at both time-points.

\section{Methods}

One-hundred and two women with suspected breast cancer recurrence or with verified local recurrence and potential distant disease were enrolled in the study. The patients were part of a larger prospective accuracy study comparing FDG-PET/CT to conventional imaging in detecting recurrent breast cancer [33]. The prospective study was conducted at the PET centre, Odense University Hospital, Denmark, from December 2011 to September 2014. Exclusion criteria were history of other malignancies, age $<18$ years, pregnancy or breastfeeding, diabetes mellitus, or considered unable to cooperate. For further methodological details we refer to our recent publication [33].

\section{FDG-pet/CT}

Patients were required to fast for at least $6 \mathrm{~h}$ before the FDG-PET/CT scan. A maximum blood glucose level of $144 \mathrm{mg} / \mathrm{dL}$ was allowed prior to intravenous injection of $4 \mathrm{MBq} / \mathrm{kg}$ FDG. Whole-body FDG-PET/CT scans were performed $1 \mathrm{~h}$ and $3 \mathrm{~h}$ after FDG injection on a General Electric Discovery STE or Discovery RX system (GE Healthcare, Milwaukee, USA). A low-dose CT scan (140 kV, 30-110 mA; Auto- and Smart mA) was performed followed by a 3D PET scan. Acquisition time was of $2.5 \mathrm{~min} /$ frame for the $1 \mathrm{~h}$ scan and $3.5 \mathrm{~min} /$ frame for the $3 \mathrm{~h}$ scan, for patients with a normal body mass index (BMI) between $18.5 \mathrm{~kg} / \mathrm{m}^{2}$ and $24.9 \mathrm{~kg} / \mathrm{m}^{2}$. If BMI was lower or higher, the scan time was adjusted according to BMI and either decreased or increased by $1 / 2 \mathrm{~min} /$ frame, respectively. Images were reconstructed iteratively using an ordered subset expectation maximization (OSEM) algorithm, with 2 iterations, and 21 or 28 subsets, a slice thickness of $3.3 \mathrm{~mm}$ and matrix size of $128 \times 128$ (pixel size of $5.47 \mathrm{~mm}^{2}$ ) with CT-based attenuation correction and $5 \mathrm{~mm}$ Gaussian post-filtering.

\section{Reference standard}

Suspected recurrence was verified by biopsy. If biopsy was not possible, a composite reference standard comprising all available imaging procedures (MRI, CT, PET/CT, bone scan, ultrasound, x-ray and mammography) and/or clinical follow-up data over 6 months was used as gold standard, using the patients' medical files as necessary. In patients with multiple lesions, it was not possible to obtain a biopsy from all lesions for ethical reasons. The patients were categorised into groups of 'local recurrence' or 'distant recurrence' based on reference standard and in accordance with treatment decision.

\section{Image interpretation}

The scans were visually interpreted by an experienced nuclear medicine physician using the General Electric acquisition workstation. The $1 \mathrm{~h}$ and $3 \mathrm{~h}$ images were read independently. Each lesion was described with 
anatomic site and exact image number for further semiquantitative analysis. The lesions were divided into seven subgroups according to lesion site: cerebrum, lung, liver, breast, lymph node, bone and 'other' (subcutaneous and muscle metastasis).

\section{Semi-quantitative analysis}

Semi-quantitative analysis of the malignant lesions was retrospectively performed using dedicated image analysis software (ROVER ${ }^{\mathrm{m}}$, ABX, Radeberg, Germany). This software provides semi-automatic image segmentation with a model-free method for PVE correction of SUVmean values. The software performs lesion delineation within a user-defined 3D mask using fixed, peak-based thresholding to delineate the lesion region-of-interest (ROI), which represents the metabolic active tumour volume (MTV). In the following step, ROVER performs PVC using an algorithm that defines a spill-out region of the lesion ROI from which a background corrected estimate of the spill-out region is calculated and used to perform PVC of SUVmean resulting in cSUVmean. Further details regarding software algorithms are explained by Hofheinz et al. [32, 34]. The ROVER software was used in standard mode with a threshold setting of $40 \%$ of maximum 3D mask value, including a minimum ROI volume of $1 \mathrm{~cm}^{3}$ and excluding ROI intersection. SUV values were normalised to body weight. Manually placement of 3D masks was performed after visual identification of the lesion by the interpreting physician. Masks were placed 2-4 pixels beyond the visual margin of each lesion, and ROVER automatically delineated the lesion ROI and performed PVC. It automatically calculated ROI values of SUVmax, SUVmean, cSUVmean and MTV. Separate 3D masks were used for the same lesions in the $1 \mathrm{~h}$ and $3 \mathrm{~h}$ scans. If a lesion had no discernible FDG uptake in the early images, the 3D mask was placed as close as possible to the assumed origin based on anatomic orientation. A reference measurement in healthy liver tissue was obtained in all patients at both timepoints. This was performed by drawing a mask of a proximately $36 \mathrm{~cm}^{3}$ in the upper right lobe of healthy liver tissue, avoiding malignancies and organ boundaries. Potential metastatic lesions without FDG-uptake would not be registered for analysis. The difference in SUVmax, SUVmean, cSUVmean, and MTV between the two time-points were calculated as $\Delta \mathrm{SUV}=\mathrm{SUV} 3 \mathrm{~h}-\mathrm{SUV} 1 \mathrm{~h}$, and $\triangle \mathrm{MTV}=\mathrm{MTV} 3 \mathrm{~h}-\mathrm{MTV} 1 \mathrm{~h}$.

\section{Statistical analysis}

Descriptive statistics were performed for demographic variables and scanning parameters. The semiquantitative analysis parameters from the $1 \mathrm{~h}$ and $3 \mathrm{~h}$ scans were expressed as mean \pm standard deviation (SD) and range. Boxplots were used for graphical display of the data. The differences in SUVs between the two timepoints as well as the difference between SUVmean and cSUVmean measurements at each time-point were estimated together with $95 \%$ confidence intervals (CI) and $p$-values that were derived from univariate linear regression models using robust standard errors to allow for intragroup correlation (i.e. multiple lesions in the same patient). Subgroup analyses were conducted by recurrence category (distant versus local recurrence) and lesion site, where healthy liver tissue was used as the reference category. Analyses were supplemented by relative changes of mean values in groups, e.g. (mean value of $3 \mathrm{~h}$ measurements - mean value of $1 \mathrm{~h}$ measurements)/ (mean value of $1 \mathrm{~h}$ measurements)* $100 \%$.

Statistical tests were two-sided with a significance level of 5\%. Analyses were conducted with Stata/MP 14.0 (StataCorp LP, College Station, Texas 77845, USA).

\section{Results}

Of the 102 patients who initially agreed to participate in the study one patient changed her mind before FDG-PET/ $\mathrm{CT}$, another was excluded due to a previous biopsyverified bone metastasis, and a third patient did not complete the $3 \mathrm{~h}$ scan, leaving 99 women available for analysis. Forty-one of these (41.4\%) were diagnosed with recurrent breast cancer, with a total of 337 malignant lesions (mean 15, range 1-70) available for analysis. The patient and scanning characteristics are given in Table 1 .

Nineteen patients had local recurrence comprising 21 lesions, and 22 patients had distant disease with 316 lesions. All patients had at least one biopsy to verify recurrence. Biopsies were primarily taken from breast lesions. For patients with recurrent disease and multiple distant metastases, only one distant lesion was verified by biopsy due to ethical aspect. All remaining metastatic lesions were verified by the composite reference standard, as

Table 1 Patient and scanning characteristics of $1 \mathrm{~h}$ and $3 \mathrm{~h}$ FDG$\mathrm{PET} / \mathrm{CT}$, performed in the 41 patients with recurrent breast cancer

\begin{tabular}{ll}
\hline Patient characteristics & Mean \pm SD, range \\
\hline Patient age (years) & $62 \pm 4.2[57 ; 74]$ \\
Body mass index & $27 \pm 7.1[22 ; 32]$ \\
Blood glucose level (mmol/L) & $5.4 \pm 1.0[3.8 ; 7.7]$ \\
Years since treatment of primary & $6 \pm 8.2[0 ; 30]$ \\
breast cancer & \\
Scanning characteristics & \\
Dose (MBq) & $281 \pm 56.0[208 ; 401]$ \\
Time (min) between injection & $62 \pm 6.0[53 ; 80]$ \\
and early scan (1h) & $180 \pm 6.0[170 ; 200]$ \\
Time (min) between injection & \\
and late scan (3h) &
\end{tabular}


described in the method section. Distribution of lesions and biopsies are shown in Table 2.

\section{Local vs. distant recurrence}

The overall SUV measurements for all 41 patients increased, on average, significantly between $1 \mathrm{~h}$ and $3 \mathrm{~h}$, i.e., SUVmax by 1.8 (+28\% increase), SUVmean by $1.1(+28 \%)$, and cSUVmean by $2.3(+35 \%)$. Overall, MTV decreased significantly over time, particularly for patients with distant recurrence in whom it decreased by 16\%, shown in Table 3 .

The values of distant recurrence were in general about twice as high as those of local recurrence, but the relative average increase was the same for the two groups. In both groups, the relative increase in cSUVmean (35-36\%) was greater than the increase in SUVmean and SUVmax (25-28\%). Despite these average tendencies, some lesions showed reduced SUVmax values at $3 \mathrm{~h}$, i.e., 8 lesions (38\%) in patients with local recurrence and 31 lesions $(10 \%)$ in patients with distant recurrence.

\section{Changes by lesion subgroup}

Except for and the lesion group 'other', all subgroups showed a significant increase in SUVmax and SUVmean over time, compared to the reference measurements in healthy liver tissue (Fig. 1). Lymph node metastases showed the highest absolute increase in SUVmax by 2.1 [1.4-2.8] (mean, 95\% CI) (+33\%), SUVmean by 1.5 [0.1-0.7] $(+36 \%)$ and cSUVmean by 3 . 2 [2.6-3.2] (+47\%). The highest relative increase in SUVmax, SUVmean and cSUVmean over time was seen for lung metastases at 40,44 and $52 \%$, respectively. Breast lesions showed the smallest absolute increase from $1 \mathrm{~h}$ to $3 \mathrm{~h}$ in SUVmax, SUVmean and cSUVmean at $0.7[0.2-1.1](+25 \%), 0.4[0.1-0.7](+24 \%)$ and $1.2[0$. 4-1.9] (+ 42\%). Liver lesions showed the lowest relative increase in SUVmax, SUVmean and, cSUVmean of 18, 16 and $18 \%$ respectively. Reference tissue in healthy

Table 2 Distribution of 337 malignant lesions in 41 recurrent breast cancer patients, according to recurrence status and lesion site. Lesion group 'other' consisted of subcutaneous and muscle metastases

\begin{tabular}{llll}
\hline $\begin{array}{l}\text { Sites of } \\
\text { recurrence }\end{array}$ & $\begin{array}{l}\text { Number } \\
\text { of patients }\end{array}$ & $\begin{array}{l}\text { Number } \\
\text { of lesions }\end{array}$ & $\begin{array}{l}\text { Number } \\
\text { of biopsies }\end{array}$ \\
\hline Local recurrence & 19 & 21 & 19 \\
Distant recurrence & 22 & 316 & 22 \\
Cerebrum & 1 & $1(0.3 \%)$ & 1 \\
Lung & 6 & $25(7.4 \%)$ & 1 \\
Liver & 4 & $7(2.1 \%)$ & 3 \\
Breast & 23 & $27(8.0 \%)$ & 21 \\
Lymph node & 13 & $54(16.0 \%)$ & 8 \\
Bone & 18 & $213(63.2 \%)$ & 7 \\
Other & 2 & $10(3.0 \%)$ & 5 \\
\hline
\end{tabular}

liver showed a significant average decrease in SUVmax by 11 and $20 \%$, respectively.

Despite the overall increase in SUV for lesion subgroups, some lesions showed reduced SUV over time, i. e., $1(4 \%)$ in the lung, 1 (14\%) in liver, 11 (41\%) in breast, $3(6 \%)$ in lymph nodes, $22(7 \%)$ in bone and $1(10 \%)$ of the 'other' lesions. The percentages of lesions with decreased values between the two time-points were the same for SUVmax, SUVmean and cSUVmean. Due to only one cerebral metastasis, this lesion group was not considered representative and is not commented upon in the results or discussion sections. MTV decreased, on average, significantly for all lesion subgroups between $1 \mathrm{~h}$ and $3 \mathrm{~h}$; however, for liver lesions and 'other' lesions the decrease was not significant. The greatest decrease (of 43\%) in MTV was seen in breast lesions. For details regarding lesion subgroups, see supplementary data given in Additional file 1.

\section{Partial volume correction}

For all lesions as a whole, cSUVmean was significantly higher than SUVmean at both $1 \mathrm{~h}$ (mean difference of 2 . 5 equal to $63 \%$ ) and $3 \mathrm{~h}$ (3.6 equal to $71 \%$ ) except lesions 'other' and liver metastases at $1 \mathrm{~h}$, which was insignificantly higher (Table 4). For patients with local recurrence cSUVmean was $70 \%$ higher than SUVmean at $1 \mathrm{~h}$ and $84 \%$ at $3 \mathrm{~h}$ and for distant recurrence $63 \%$ higher at $1 \mathrm{~h}$ and $71 \%$ at $3 \mathrm{~h}$, see Table 4 .

At lesion site the largest difference was at $3 \mathrm{~h}$ for breast lesions, where cSUVmean was $87 \%$ higher than SUVmean. The smallest difference was at $1 \mathrm{~h}$ for liver lesions, in which cSUVmean was 39\% higher than SUVmean (Table 4). Generally, cSUVmean varied more than SUVmean in all lesion sites (Fig. 2). Further details regarding lesion subgroups, see supplementary data given in Additional file 1.

\section{Discussion}

This study of malignant lesions in 41 out of 99 analysed patients with breast cancer recurrence showed significant overall increase in uptake of FDG between $1 \mathrm{~h}$ and $3 \mathrm{~h}$ scans. The values of distant recurrence were in general about twice as high as those of local recurrence, but the relative increase was the same for the two groups (Table 3). Lymph node metastases showed the highest absolute increase in SUV between the two time-points, whereas lung metastases displayed the highest relative increase. PVC led to higher uptake estimates, especially for patients with local recurrence and for breast lesions at the $3 \mathrm{~h}$ scan (Table 4 and Fig. 2). We found decreased SUV over time in reference tissue (healthy liver) as expected and hence an increased tumour-to-background ratio for delayed imaging. 
Table 3 Standard uptake values (SUVmax, SUVmean, partial volume corrected SUVmean (cSUVmean) and MTV of malignant lesions at $1 \mathrm{~h}$ and $3 \mathrm{~h}$ (mean \pm SD, min and max), and the change over time ( $\triangle \mathrm{SUV}$ with $95 \% \mathrm{Cl}$ ) by patient recurrence status. $\Delta$ SUV\% and $\triangle M T V \%$ were calculated by using mean values of $1 \mathrm{~h}$ and $3 \mathrm{~h}$ groups. $P$-values refer to the hypothesis test that the mean difference of the paired observations at $1 \mathrm{~h}$ and $3 \mathrm{~h}$ is equal to 0

\begin{tabular}{|c|c|c|c|c|c|}
\hline & $1 \mathrm{~h}$ & $3 h$ & $\triangle S U V(3 h-1 h)$ & $p$-value & $\triangle S U V \%$ \\
\hline \multicolumn{6}{|c|}{ All 41 patients with recurrence (337 lesions) } \\
\hline SUVmax & $\begin{array}{l}6.4 \pm 3.4 \\
{[0.9-19.7]}\end{array}$ & $\begin{array}{l}8.1 \pm 4.4 \\
{[0.7-29.7]}\end{array}$ & $\begin{array}{l}1.8 \\
{[1.5 \text { to } 2.1]}\end{array}$ & $<0.0001$ & 28 \\
\hline SUVmean & $\begin{array}{l}4.0 \pm 2.0 \\
{[0.5-11.3]}\end{array}$ & $\begin{array}{l}5.1 \pm 2.6 \\
{[0.4-16.5]}\end{array}$ & $\begin{array}{l}1.1 \\
{[1.0 \text { to } 1.3]}\end{array}$ & $<0.0001$ & 28 \\
\hline cSUVmean & $\begin{array}{l}6.5 \pm 3.5 \\
{[0.7-20.8]}\end{array}$ & $\begin{array}{l}8.8 \pm 4.7 \\
{[0.5-30.9]}\end{array}$ & $\begin{array}{l}2.3 \\
{[1.9 \text { to } 2.6]}\end{array}$ & $<0.0001$ & 35 \\
\hline MTV (cc) & $\begin{array}{l}12.5 \pm 42.4 \\
{[0.3-562]}\end{array}$ & $\begin{array}{l}10.4 \pm 39.9 \\
{[0.2-565.5]}\end{array}$ & $\begin{array}{l}-2.1 \\
{[-3.1 \text { to }-1.0]}\end{array}$ & $<0.0001$ & -17 \\
\hline \multicolumn{6}{|c|}{19 patients with local recurrence (21 lesions) } \\
\hline SUVmax & $\begin{array}{l}3.0 \pm 1.9 \\
{[0.9-8.7]}\end{array}$ & $\begin{array}{l}3.8 \pm 3.0 \\
{[0.7-12.3]}\end{array}$ & $\begin{array}{l}0.8 \\
{[0.2 \text { to } 1.4]}\end{array}$ & 0.006 & 27 \\
\hline SUVmean & $\begin{array}{l}1.9 \pm 1.3 \\
{[0.5-5.9]}\end{array}$ & $\begin{array}{l}2.4 \pm 2.0 \\
{[0.4-8.6]}\end{array}$ & $\begin{array}{l}0.5 \\
{[0.08 \text { to } 0.9]}\end{array}$ & 0.022 & 25 \\
\hline cSUVmean & $\begin{array}{l}3.2 \pm 2.4 \\
{[0.7-8.9]}\end{array}$ & $\begin{array}{l}4.4 \pm 3.9 \\
{[0.5-14.4]}\end{array}$ & $\begin{array}{l}1.2 \\
{[0.3 \text { to } 2.1]}\end{array}$ & 0.014 & 36 \\
\hline MTV (cc) & $\begin{array}{l}8.4 \pm 10.3 \\
{[0.3-33.3]}\end{array}$ & $\begin{array}{l}5.7 \pm 5.5 \\
{[0.2-22.3]}\end{array}$ & $\begin{array}{l}-2.8 \\
{[-6.2 \text { to } 0.7]}\end{array}$ & 0.11 & -33 \\
\hline \multicolumn{6}{|c|}{22 patients with distant recurrence (316 lesions) } \\
\hline SUVmax & $\begin{array}{l}6.6 \pm 3.3 \\
{[1.2-19.7]}\end{array}$ & $\begin{array}{l}8.4 \pm 4.4 \\
{[1.2-29.7]}\end{array}$ & $\begin{array}{l}1.8 \\
{[1.5 \text { to } 2.2]}\end{array}$ & $<0.0001$ & 28 \\
\hline SUVmean & $\begin{array}{l}4.1 \pm 2.0 \\
{[0.8-11.3]}\end{array}$ & $\begin{array}{l}5.3 \pm 2.6 \\
{[0.6-16.5]}\end{array}$ & $\begin{array}{l}1.2 \\
{[1.0 \text { to } 1.4]}\end{array}$ & $<0.0001$ & 28 \\
\hline cSUVmean & $\begin{array}{l}6.7 \pm 3.5 \\
{[0.8-20.8]}\end{array}$ & $\begin{array}{l}9.1 \pm 4.6 \\
{[0.8-30.9]}\end{array}$ & $\begin{array}{l}2.3 \\
{[2.0 \text { to } 2.7]}\end{array}$ & $<0.0001$ & 35 \\
\hline MTV (cc) & $\begin{array}{l}12.8 \pm 43.7 \\
{[0.4-562.0]}\end{array}$ & $\begin{array}{l}10.7 \pm 41.1 \\
{[0.2-565.5]}\end{array}$ & $\begin{array}{l}-2.1 \\
{[-3.2 \text { to }-0.9]}\end{array}$ & 0.001 & -16 \\
\hline
\end{tabular}

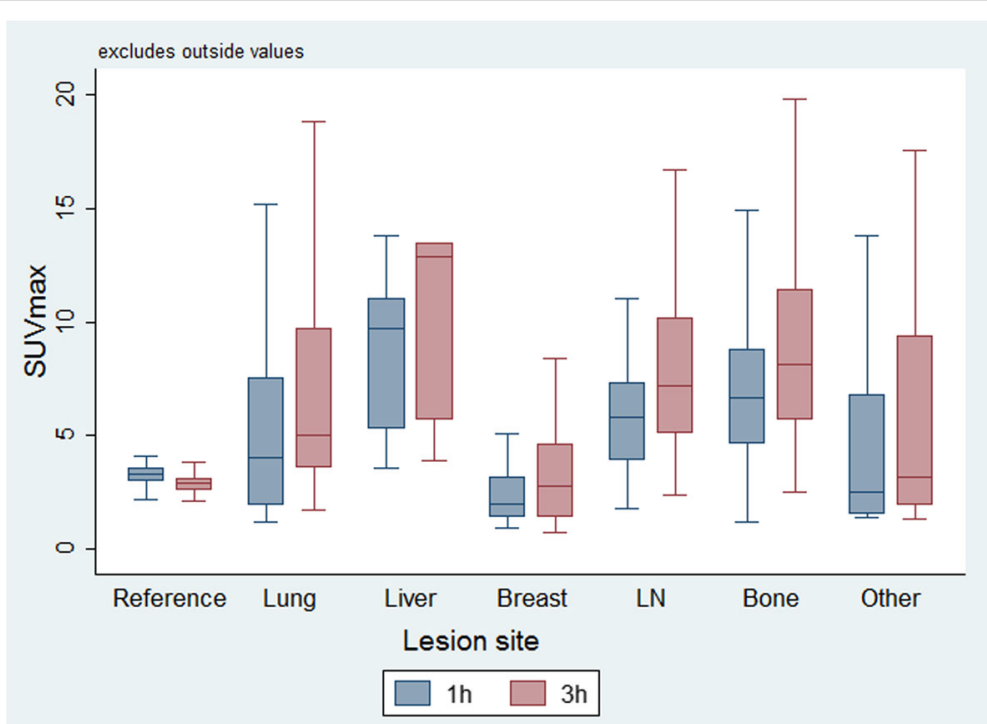

Fig. 1 Boxplots of SUVmax, at $1 \mathrm{~h}$ and $3 \mathrm{~h}$ imaging time-point, for the 337 malignant lesions according to the different subgroups and reference tissue (healthy liver) in 41 patients with recurrent breast cancer. Due to only one cerebral lesion, data are not shown for this group 
Table 4 Difference between SUVmean and cSUVmean for $1 \mathrm{~h}$ and $3 \mathrm{~h}$ measurements for all lesions according to recurrent status and lesion subgroups (mean and 95\% Cl). Percentage difference was calculated by using mean values of cSUVmean and SUVmean groups for $1 \mathrm{~h}$ and $3 \mathrm{~h}$. P-values refer to the hypothesis test that the mean difference of the paired observations at each time-point for SUVmean and cSUVmean is equal to 0

\begin{tabular}{|c|c|c|c|c|c|c|}
\hline Group & $\begin{array}{l}\text { Difference } 1 \mathrm{~h} \\
\text { (cSUVmean-SUVmean) }\end{array}$ & $p$-value & $\%$ diff & $\begin{array}{l}\text { Difference 3h } \\
\text { (cSUVmean-SUVmean) }\end{array}$ & $p$-value & $\%$ diff \\
\hline $\begin{array}{l}\text { All lesions } \\
\text { (337 lesions) }\end{array}$ & $\begin{array}{l}2.51 \\
{[2.14-2.88]}\end{array}$ & $<0.0001$ & 63 & $\begin{array}{l}3.64 \\
{[3.22-4.06]}\end{array}$ & $<0.0001$ & 71 \\
\hline $\begin{array}{l}\text { Local recurrence } \\
\text { (21 lesions) }\end{array}$ & $\begin{array}{l}1.32 \\
{[0.74-1.91]}\end{array}$ & $<0.0001$ & 70 & $\begin{array}{l}2.02 \\
{[1.07-2.98]}\end{array}$ & $<0.0001$ & 84 \\
\hline $\begin{array}{l}\text { Distant recurrence } \\
\text { ( } 316 \text { lesions) }\end{array}$ & $\begin{array}{l}2.59 \\
{[2.21-2.98]}\end{array}$ & $<0.0001$ & 63 & $\begin{array}{l}3.75 \\
{[3.32-4.18]}\end{array}$ & $<0.0001$ & 71 \\
\hline $\begin{array}{l}\text { Lung } \\
\text { (25 lesions) }\end{array}$ & $\begin{array}{l}1.88 \\
{[0.48-3.27]}\end{array}$ & 0.018 & 60 & $\begin{array}{l}3.09 \\
{[1.28-4.91]}\end{array}$ & 0.007 & 68 \\
\hline $\begin{array}{l}\text { Liver } \\
\text { (7 lesions) }\end{array}$ & $\begin{array}{l}2.17 \\
{[-0.80-5.14]}\end{array}$ & 0.103 & 39 & $\begin{array}{l}2.67 \\
{[0.91-4.44]}\end{array}$ & 0.017 & 41 \\
\hline $\begin{array}{l}\text { Breast } \\
\text { (27 lesions) }\end{array}$ & $\begin{array}{l}1.09 \\
{[0.59-1.60]}\end{array}$ & $<0.0001$ & 63 & $\begin{array}{l}1.86 \\
{[1.06-2.66]}\end{array}$ & $<0.0001$ & 87 \\
\hline $\begin{array}{l}\text { Lymph node } \\
\text { (54 lesions) }\end{array}$ & $\begin{array}{l}2.77 \\
{[1.62-3.92]}\end{array}$ & $<0.0001$ & 69 & $\begin{array}{l}4.49 \\
{[3.16-5.82]}\end{array}$ & $<0.0001$ & 82 \\
\hline $\begin{array}{l}\text { Bone } \\
\text { ( } 213 \text { lesions) }\end{array}$ & $\begin{array}{l}2.73 \\
{[2.43-2.92]}\end{array}$ & $<0.0001$ & 63 & $\begin{array}{l}3.80 \\
{[3.45-4.14]}\end{array}$ & $<0.0001$ & 69 \\
\hline $\begin{array}{l}\text { Other } \\
\text { (10 lesions) }\end{array}$ & $\begin{array}{l}2.32 \\
{[-21.82-26.46]}\end{array}$ & 0.437 & 78 & $\begin{array}{l}2.73 \\
{[-21.54-27.00]}\end{array}$ & 0.389 & 73 \\
\hline
\end{tabular}

Although our study, in line with previous literature, demonstrated an increased tumour-to-background ratio in delayed images, the diagnostic accuracy at patient level did not improve in our overall prospective accuracy study [33]. The clinical usefulness of delayed imaging in this category of patients may thus be limited. Furthermore, it is our experience that DTPI caused planning challenges in daily workflow and patient discomfort due to a longer fasting period.

\section{Change in SUV from early to late time-point imaging}

Patients with local recurrence had in general lower SUVmax and SUVmean measurements compared to the group with distant recurrence at both time-points. This

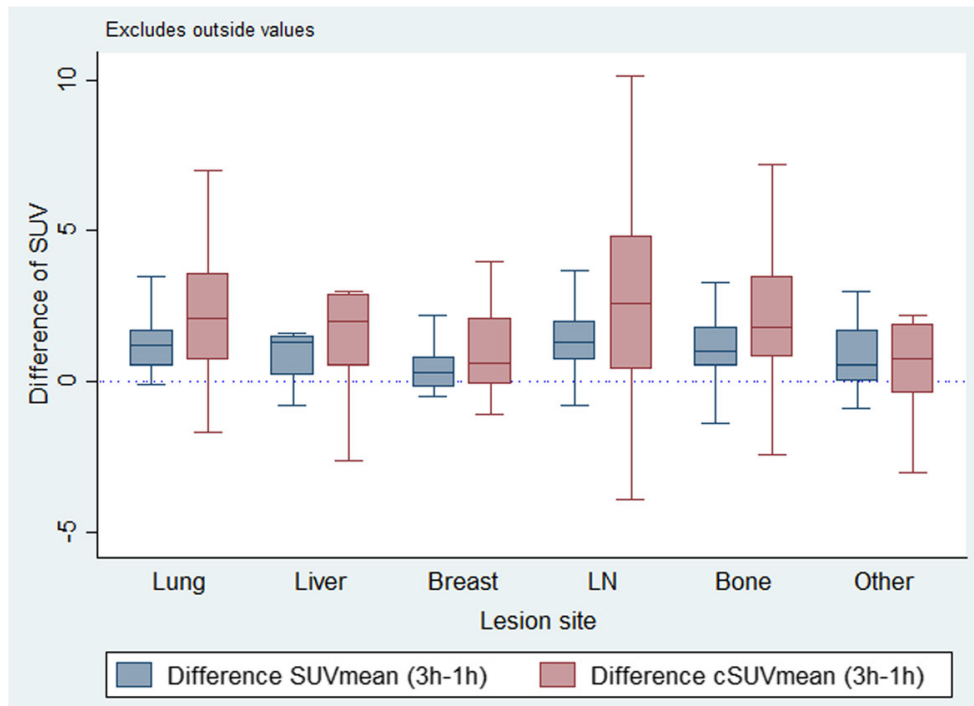

Fig. 2 Boxplots visualising the difference from $1 \mathrm{~h}$ to $3 \mathrm{~h}$ in SUVmean and cSUVmean for malignant lesions, according to different subgroups and reference tissue. The difference between the two time-points were calculated as $\triangle S U V=S U V 3 h$ - SUV1h. Due to only one cerebral lesion, data are not shown for this group 
could partly be due to the finding that 8 of the 21 lesions (38\%) in the group with local recurrence showed decreased SUV from $1 \mathrm{~h}$ to $3 \mathrm{~h}$ compared to only $10 \%$ in patients with distant recurrence. Suga et al. reported similar results from 52 patients with suspected local recurrence of breast cancer, where SUVmax increased in $84 \%$ of the lesions and decreased in $16 \%$ of the lesions between $1 \mathrm{~h}$ and $2 \mathrm{~h}$ scans, while overall SUVmax increased by 18\% [35]. The higher increase in SUVmax in our study could be due to the later imaging point at $3 \mathrm{~h}$. Several studies have performed delayed or dual-time imaging in breast cancer but have only shown a small improvement in detecting local recurrence, despite an increased tumour-to-background ratio [11, 12, 36, 37].

Distant metastases in lung, lymph node, liver and bone all increased in SUVmax, SUVmean, and cSUVmean from $1 \mathrm{~h}$ to $3 \mathrm{~h}$, and especially for lymph node metastases. These findings are supported by the literature, where several publications have stated the increased FDG accumulation over time in different malignant lesions [7, 16, 17, 35].

In our study, we used healthy liver tissue for reference measurement, which has previously been demonstrated useful by Chirindel et al. [38]. For bone metastases, we found a significant increase for SUVmax, SUVmean, and cSUVmean between $1 \mathrm{~h}$ and $3 \mathrm{~h}$. These findings are supported by a study of bone metastases in breast cancer patients from Tian et al. [39]. Other diagnostic studies of bone metastases and FDG-PET/CT have found that FDG has a high sensitivity for detecting osteolytic and mixed bone lesions compared to osteoblastic lesions, which can be false-negative due to low metabolic activity [40, 41].

SUV can be influenced by a range of physiological and technical parameters, which should be taken in consideration by quantitative image analysis, to minimize bias [42-44]. SUVmax demonstrates a high inter-observer reproducibility and is often used as a semi-quantitative measure of FDG-uptake. However, SUVmax is more sensitive to image noise, and has been shown to have a lower inter-study repeatability than SUVmean [45, 46]. While SUVmean may be a more reliable measure in heterogeneous tumours, it can be observer-dependent due to lesion delineation dependency with variability in mask placement and sensitivity to PVE, especially in smaller lesions [26, 27, 47].

\section{Impact of PVC performed with ROVER software}

PVC of SUVmean had as expected a significant impact in our study, in both the overall lesion group and the various subgroups. However, PVC increased the standard deviation of cSUVmean compared to uncorrected SUVmean, probably due to incorrect lesion delineation caused by segmentation challenges (Fig. 2). The highest impact of PVC was seen for breast lesions which also had the smallest MTV according to ROVER. Our results agree with the literature, showing that partial volume effects influence measured uptake in all lesions, especially those smaller or of a size close to the limited spatial resolution of the PET scanner, for which it causes a significant underestimation of lesion extent and activity level $[26,27,47]$.

Several studies have demonstrated observer-related variability associated with manual delineation of ROI, which can be reduced by the use of automatic or semi-automatic contour drawing [48-50]. Prevalently employed automatic delineation methods employing different threshold and cut-offs, however, are also known to be suboptimal in many cases, leading to segmentation bias $[20,49]$. We used ROVER software for PVC, which has previously been shown to be feasibly and clinically useful [31, 34]. ROVER software included background subtraction for each lesion, but despite this we discovered practical challenges due to non-uniformity of lesions and background activity. We experienced against expectation a decrease in MTV defined by ROVER from $1 \mathrm{~h}$ to $3 \mathrm{~h}$, despite the general known tendency of increased FDG accumulation over time in malignant lesions. This issue was probably caused by crucial segmentation challenges associated with the semiautomatic lesion delineation. Thus, by visual inspection of the automatic lesion delineation in our study, the lesion ROI in the $1 \mathrm{~h}$ image often included background voxels and thereby overestimated lesion size, compared to the same lesion in the $3 \mathrm{~h}$ image, where the lesion delineation appeared more well-defined (Fig. 3). This indicates that the threshold-based segmentation in ROVER led to overestimated volumes of small lesions, particularly in the early scan, where the lesion-to-background ratio was low, and through that an underestimation of SUVmean. We used a fixed $40 \%$ threshold setting to semi-automatically delineate lesions. This approach was based on the current use in the literature and similar to the threshold of $41 \%$ recommended by updated European guidelines [48, 51]. A more systematic search of other threshold levels or rather alternative segmentation methods that can provide more accurate lesion delineation could be beneficial [32, 42, 49], but lies outside the scope of this article.

\section{Strengths and limitations of the study}

The main strengths of our study are its prospective design and clinically representative patient group with newly diagnosed recurrence - verified by biopsy in all patients and, hence, yet untreated metastases. The scanning protocol consisted of whole-body scans at both $1 \mathrm{~h}$ and $3 \mathrm{~h}$ allowing us to compare SUV measurements over time in all recurrent lesions. A major limitation was that histological proof was not available for all lesions due to ethical and practical reasons, and therefore a composite reference 


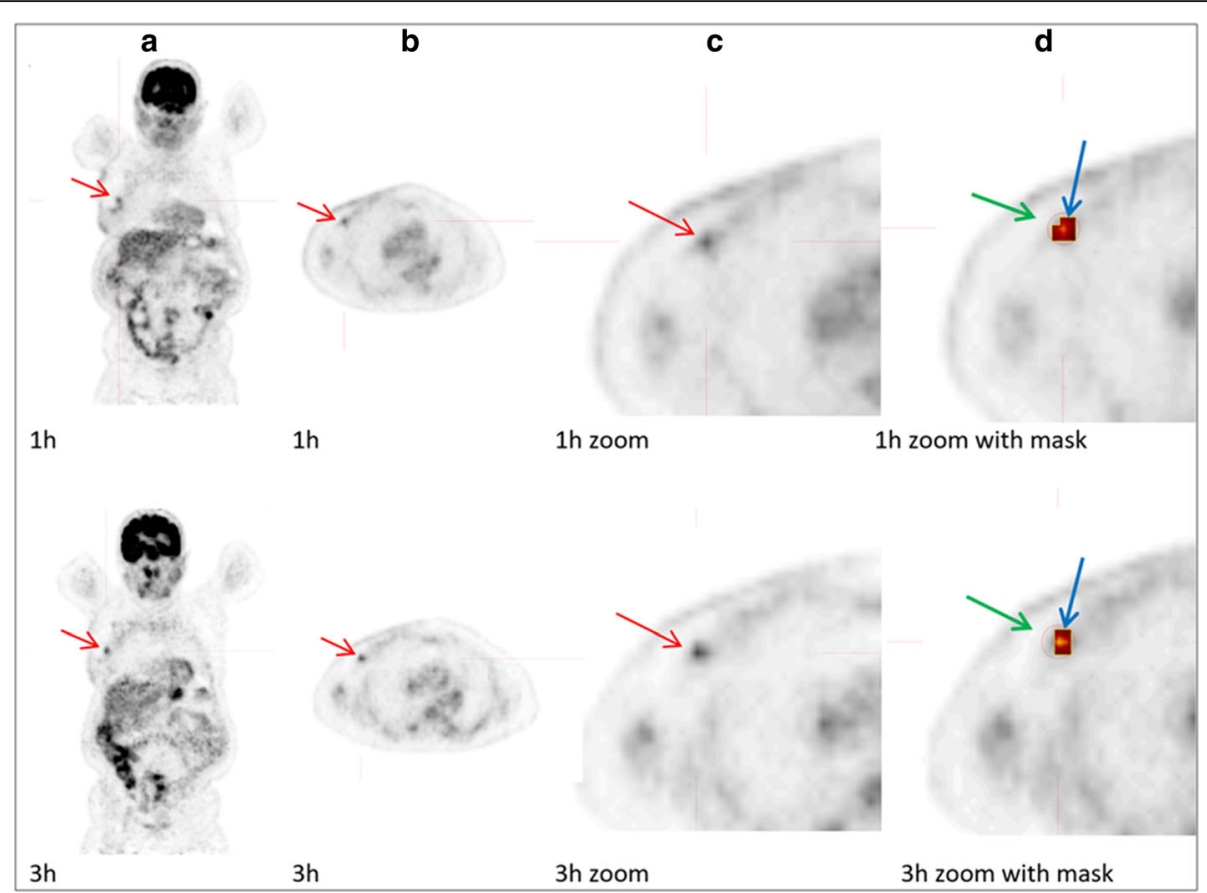

Fig. 3 FDG-PET/CT images of a 73 years old woman with local recurrence in her right breast (red arrow) displayed in ROVER. a Maximum intensity

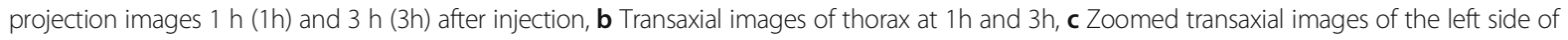
thorax at $1 \mathrm{~h}$ and $3 \mathrm{~h}$, and $\mathbf{d}$ Zoomed transaxial images with masks at $1 \mathrm{~h}$ and $3 \mathrm{~h}$, where the green arrow shows the user defined 3D mask (equal mask size at $1 \mathrm{~h}$ and $3 \mathrm{~h}$ images), and the blue arrow shows the lesion ROI delineated by the ROVER software, which yielded the following values after $1 \mathrm{~h}$ and 3h, respectively: MTV (cc) 3.8 and 2.1; SUVmax 3.2 and 3.7; SUVmean 1.8 and 2.6; CSUVmean 2.3 and 5.1

standard was the best option. Another limitation was the observed suboptimal segmentation with a fixed $40 \%$ of maximum value threshold. Segmentation methods using separate masks for $1 \mathrm{~h}$ and $3 \mathrm{~h}$ images in each patient were associated with challenges such as spatial mismatch between $1 \mathrm{~h}$ and $3 \mathrm{~h}$ acquisitions. This could contribute to segmentation variability and potentially incorrect comparison of quantitative results from the two time-points. Being the outcome of a single institution study, the generalizability of our results is uncertain.

The overall intention with this study was to consider whether a $3 \mathrm{~h}$ scan should replace the $1 \mathrm{~h}$ standard imaging in patients with metastatic breast cancer. Although we found an increased tumour-to-background ratio in $3 \mathrm{~h}$ compared to $1 \mathrm{~h}$ scans, this was not associated with improved diagnostic accuracy on a per-patient level as shown in our previous publication [33]. Furthermore, $3 \mathrm{~h}$ protocols cause challenges regarding planning, patient discomfort and healthcare costs. Based on these experiences, it may not be justified to replace the standard $1 \mathrm{~h}$ by a delayed imaging protocol.

\section{Conclusion}

SUVs of FDG increased significantly from $1 \mathrm{~h}$ to $3 \mathrm{~h}$ in malignant lesions of recurrent breast cancer and in all types of lesions, while reference measurements in healthy liver tissue decreased. PVC increased these values significantly as expected, especially in breast metastases. However, the demonstrated modest quantitative advances of $3 \mathrm{~h}$ imaging can hardly justify delayed PET imaging on a routine basis in this patient group.

\section{Additional file}

Additional file 1: SUV lesion measures for various subgroups. SUV and MTV for all malignant lesion according to the different subgroups at $1 \mathrm{~h}$ and $3 \mathrm{~h}$, and the change over time. (PDF $232 \mathrm{~kb}$ )

\section{Abbreviations}

1h: 1 h; 3h: 3 h; BMl: Body mass index; Cl: Confidence interval; cSUVmean: Partial volume corrected SUVmean; CT: Computed tomography; DTPI: Delayed timepoint imaging; FDG-PET/CT: ${ }^{18} \mathrm{~F}$-fluoro-deoxy-glucose positron emission tomography/computed tomography G6PaseGlucose-6-phosphatase; MBq: Mega Becquerel; MRI: Magnetic resonance imaging; MTV: Metabolic active tumour volume; OSEM: Ordered subset expectation maximization; PVC: Partial volume correction; PVE: Partial volume effect; ROI: Region-ofinterest; SD: Standard deviation; SUV: Standard uptake values; SUVmax: Maximum standard uptake value; SUVmean: Mean standard uptake value

\section{Acknowledgements}

The authors would like to express their gratitude towards two reviewers whose comments significantly improved former versions of the manuscript. Moreover, the authors acknowledge the support of the staff at the Department of Nuclear Medicine, Odense University Hospital, Denmark. Special thanks to 
the PET/CT technologists for technical assistance with the imaging studies and to Birgitte B. Olsen for ongoing constructive feedback on the project.

\section{Funding}

The project was implemented without the involvement of private organizations or companies.

\section{Availability of data and materials}

The datasets used and analysed during the current study are available from the corresponding author on reasonable request.

\section{Authors' contributions}

$\mathrm{CB}, \mathrm{MGH}, \mathrm{KF}$ AA and PFC conceptualised and designed the study $\mathrm{CB}$ and $\mathrm{MGH}$ acquired and analysed data and drafted the manuscript. KF acquired and analysed data. JH and OG analysed and interpreted data. PFHC, AA, OG and TON enhanced the intellectual content of and reviewed the manuscript. All authors have read and approved the final version of the manuscript.

\section{Ethics approval and consent to participate}

The study was conducted in compliance with good clinical practice and the Declaration of Helsinki and written informed consent was obtained from all included patients. The study where approved by the Science Ethics Committees for the Capital Region of Denmark (protocol number: S-20110138), and registered at ClinicalTrails.gov (NCT01552655).

\section{Competing interests}

The authors declare that they have no competing interests.

\section{Publisher's Note}

Springer Nature remains neutral with regard to jurisdictional claims in published maps and institutional affiliations.

\section{Author details}

${ }^{1}$ Department of Nuclear Medicine, University Hospital, Sdr. Boulevard 29, 5000 Odense C, Denmark. ${ }^{2}$ Centre of Health Economics Research, University of Southern Denmark, Odense, Denmark. ${ }^{3}$ University of Pennsylvania, Philadelphia, USA.

\section{Received: 11 May 2017 Accepted: 30 April 2018} Published online: 09 May 2018

\section{References}

1. Jemal A, Bray F, Center MM, Ferlay J, Ward E, Forman D. Global cancer statistics. CA Cancer J Clin. 2011;61(2):69-90.

2. International Agency for Research on Cancer, Globocan 2012. http:// globocan.iarc.fr/Pages/fact_sheets_cancer.aspx. Accessed 11 May 2016.

3. Groheux D, Espie M, Giacchetti S, Hindie E. Performance of FDG PET/CT in the clinical management of breast cancer. Radiology. 2013;266(2):388-405.

4. Pennant M, Takwoingi Y, Pennant L, Davenport C, Fry-Smith A, Eisinga A, Andronis L, Arvanitis T, Deeks J, Hyde C. A systematic review of positron emission tomography (PET) and positron emission tomography/computed tomography (PET/CT) for the diagnosis of breast cancer recurrence. Health Technol Asses. 2010;14(50):1-103.

5. Eubank WB, Mankoff DA, Vesselle HJ, Eary JF, Schubert EK, Dunnwald LK, Lindsley SK, Gralow JR, Austin-Seymour MM, Ellis GK, et al. Detection of locoregional and distant recurrences in breast cancer patients by using FDG PET. Radiographics. 2002;22(1):5-17.

6. Cheng $G$, Torigian DA, Zhuang $H$, Alavi A. When should we recommend use of dual time-point and delayed time-point imaging techniques in FDG PET? Eur J Nucl Med Mol I. 2013;40(5):779-87.

7. Matthies A, Hickeson M, Cuchiara A, Alavi A. Dual time point 18F-FDG PET for the evaluation of pulmonary nodules. J Nucl Med. 2002;43(7):871-5.

8. Houshmand S, Salavati A, Segtnan EA, Grupe P, Hoilund-Carlsen PF, Alavi A. Dualtime-point imaging and delayed-time-point Fluorodeoxyglucose-PET/computed tomography imaging in various clinical settings. PET Clin. 2016;11(1):65-84.

9. Cheng G, Alavi A, Lim E, Werner TJ, Del Bello CV, Akers SR. Dynamic changes of FDG uptake and clearance in normal tissues. Mol Imaging Biol. 2013;15(3):345-52.

10. Gillies RJ, Robey I, Gatenby RA. Causes and consequences of increased glucose metabolism of cancers. J Nucl Med. 2008;49(Suppl 2):24s-42s.
11. Boerner AR, Weckesser M, Herzog H, Schmitz T, Audretsch W, Nitz U, Bender HG, Mueller-Gaertner HW. Optimal scan time for fluorine-18 fluorodeoxyglucose positron emission tomography in breast cancer. Eur J Nucl Med. 1999:26(3):226-30.

12. Kumar R, Loving VA, Chauhan A, Zhuang H, Mitchell S, Alavi A. Potential of dual-time-point imaging to improve breast cancer diagnosis with (18)F-FDG PET. J Nucl Med. 2005;46(11):1819-24

13. Mavi A, Urhan M, Yu JQ, Zhuang H, Houseni M, Cermik TF, Thiruvenkatasamy D, Czerniecki B, Schnall M, Alavi A. Dual time point 18FFDG PET imaging detects breast cancer with high sensitivity and correlates well with histologic subtypes. J Nucl Med. 2006:47(9):1440-6.

14. Beaulieu S, Kinahan P, Tseng J, Dunnwald LK, Schubert EK, Pham P, Lewellen B, Mankoff DA. SUV varies with time after injection in (18)F-FDG PET of breast cancer: characterization and method to adjust for time differences. J Nucl Med. 2003:44(7):1044-50.

15. Basu S, Mavi A, Cermik T, Houseni M, Alavi A. Implications of standardized uptake value measurements of the primary lesions in proven cases of breast carcinoma with different degree of disease burden at diagnosis: does $2-$ deoxy-2-[F-18]fluoro-D-glucose-positron emission tomography predict tumor biology? Mol Imaging Biol. 2008;10(1):62-6.

16. Chan WL, Ramsay SC, Szeto ER, Freund J, Pohlen JM, Tarlinton LC, Young A, Hickey A, Dura R. Dual-time-point (18)F-FDG-PET/CT imaging in the assessment of suspected malignancy. J Med Imag Radiat On. 2011;55(4):379-90.

17. Lee JW, Kim SK, Lee SM, Moon SH, Kim TS. Detection of hepatic metastases using dual-time-point FDG PET/CT scans in patients with colorectal cancer. Mol Imaging Biol. 2011;13(3):565-72.

18. Basu S, Alavi A. Partial volume correction of standardized uptake values and the dual time point in FDG-PET imaging: should these be routinely employed in assessing patients with cancer? Eur J Nucl Med Mol I. 2007; 34(10):1527-9.

19. Kadoya T, Aogi K, Kiyoto S, Masumoto N, Sugawara Y, Okada M. Role of maximum standardized uptake value in fluorodeoxyglucose positron emission tomography/computed tomography predicts malignancy grade and prognosis of operable breast cancer: a multi-institute study. Breast Cancer Res Tr. 2013: 141(2):269-75

20. Vriens D, Visser EP, de Geus-Oei LF, Oyen WJ. Methodological considerations in quantification of oncological FDG PET studies. Eur J Nucl Med Mol I. 2010;37(7):1408-25.

21. Gamez-Cenzano C, Pino-Sorroche F. Standardization and quantification in FDG-PET/CT imaging for staging and restaging of malignant disease. PET Clin. 2014;9(2):117-27.

22. Basu S, Zaidi H, Houseni M, Bural G, Udupa J, Acton P, Torigian DA, Alavi A. Novel quantitative techniques for assessing regional and global function and structure based on modern imaging modalities: implications for normal variation, aging and diseased states. Semin Nucl Med. 2007:37(3):223-39.

23. Groheux D, Giacchetti S, Moretti JL, Porcher R, Espie M, Lehmann-Che J, de Roquancourt A, Hamy AS, Cuvier C, Vercellino L, et al. Correlation of high 18F-FDG uptake to clinical, pathological and biological prognostic factors in breast cancer. Eur J Nucl Med Mol I. 2011:38(3):426-35.

24. Morris PG, Ulaner GA, Eaton A, Fazio M, Jhaveri K, Patil S, Evangelista L, Park JY, Serna-Tamayo C, Howard J, et al. Standardized uptake value by positron emission tomography/computed tomography as a prognostic variable in metastatic breast cancer. Cancer. 2012;118(22):5454-62.

25. Garcia Vicente AM, Soriano Castrejon A, Leon Martin A, Chacon Lopez-Muniz I, Munoz Madero V. Munoz Sanchez Mdel M, Palomar Munoz a, Espinosa Aunion R, Gonzalez Ageitos a: molecular subtypes of breast cancer: metabolic correlation with (1)(8)F-FDG PET/CT. Eur J Nucl Med Mol I. 2013;40(9):1304-11.

26. Soret M, Bacharach SL, Buvat I. Partial-volume effect in PET tumor imaging. Nucl Med. 2007:48(6):932-45

27. Hoetjes NJ, van Velden FH, Hoekstra OS, Hoekstra CJ, Krak NC, Lammertsma AA, Boellaard R. Partial volume correction strategies for quantitative FDG PET in oncology. Eur J Nucl Med Mol I. 2010;37(9):1679-87.

28. Gallivanone F, Canevari C, Sassi I, Zuber V, Marassi A, Gianolli L, Picchio M, Messa C, Gilardi MC, Castiglioni I. Partial volume corrected 18F-FDG PET mean standardized uptake value correlates with prognostic factors in breast cancer. Q J Nucl Med. 2014:58(4):424-39.

29. Aston JA, Cunningham VJ, Asselin MC, Hammers A, Evans AC, Gunn RN. Positron emission tomography partial volume correction: estimation and algorithms. J Cerebr Blood F Met. 2002;22(8):1019-34.

30. Boussion N, Hatt M, Lamare F, Bizais Y, Turzo A, Cheze-Le Rest C, Visvikis D. A multiresolution image based approach for correction of 
partial volume effects in emission tomography. Phys Med Biol. 2006; 51(7):1857-76.

31. Torigian DA, Lopez RF, Alapati S, Bodapati G, Hofheinz F, van den Hoff J, Saboury B, Alavi A. Feasibility and performance of novel software to quantify metabolically active volumes and 3D partial volume corrected SUV and metabolic volumetric products of spinal bone marrow metastases on 18F-FDG-PET/CT. Hell J Nuc Med. 2011;14(1):8-14.

32. Hofheinz F, Langner J, Petr J, Beuthien-Baumann B, Oehme L, Steinbach J, Kotzerke J, van den Hoff J. A method for model-free partial volume correction in oncological PET. Eur J Nucl Med Mol I Research. 2012;2(1):16.

33. Hildebrandt MG, Gerke O, Baun C, Falch K, Hansen JA, Farahani ZA, Petersen H, Larsen LB, Duvnjak S, Buskevica I, et al. [18F]Fluorodeoxyglucose (FDG)-positron emission tomography (PET)/computed tomography (CT) in suspected recurrent breast Cancer: a prospective comparative study of dual-time-point FDG-PET/CT, contrast-enhanced $C$, and bone scintigraphy. J Clin Oncol. 2016;34:1889-97.

34. Hofheinz F, Potzsch C, Oehme L, Beuthien-Baumann B, Steinbach J, Kotzerke $J$, van den Hoff J. Automatic volume delineation in oncological PET. Evaluation of a dedicated software tool and comparison with manual delineation in clinical data sets. Nuklearmedizin. 2012;51 (1):9-16.

35. Suga K, Kawakami Y, Hiyama A, Matsunaga N. Differentiation of FDG-avid loco-regional recurrent and compromised benign lesions after surgery for breast cancer with dual-time point F-18-fluorodeoxy-glucose PET/CT scan. Ann Nucl Med. 2009;23(4):399-407.

36. Caprio MG, Cangiano A, Imbriaco M, Soscia F, Di Martino G, Farina A, Avitabile G, Pace L, Forestieri P, Salvatore M. Dual-time-point [18F]-FDG PET/CT in the diagnostic evaluation of suspicious breast lesions. Radiol Med. 2010;115:215-24.

37. Choi WH, Yoo IR, JH O, Kim SH, Chung SK. The value of dual-time-point 18F-FDG PET/CT for identifying axillary lymph node metastasis in breast cancer patients. Brit J Rad. 2011;84(1003):593-9.

38. Chirindel A, Alluri KC, Tahari AK, Chaudhry M, Wahl RL, Lodge MA, Subramaniam RM. Liver standardized uptake value corrected for lean body mass at FDG PET/CT: effect of FDG uptake time. Clin Nucl Med. 2015;40(1):e17-22.

39. Tian R, Su M, Tian Y, Li F, Li L, Kuang A, Zeng J. Dual-time point PET/CT with F-18 FDG for the differentiation of malignant and benign bone lesions. Skelet Radiol. 2009;38(5):451-8.

40. Hamaoka T, Madewell JE, Podoloff DA, Hortobagyi GN, Ueno NT. Bone imaging in metastatic breast cancer. J Clin Oncol. 2004;22(14):2942-53.

41. Cook GJ, Houston S, Rubens R, Maisey MN, Fogelman I. Detection of bone metastases in breast cancer by 18FDG PET: differing metabolic activity in osteoblastic and osteolytic lesions. J Clin Oncol. 1998;16(10):3375-9.

42. Boellaard R, Krak NC, Hoekstra OS, Lammertsma AA. Effects of noise, image resolution, and $\mathrm{ROI}$ definition on the accuracy of standard uptake values: a simulation study. J Nucl Med. 2004;45(9):1519-27.

43. Huang SC. Anatomy of SUV. Standardized uptake value. Nucl Med Biol. 2000;27(7):643-6.

44. Keyes JW Jr. SUV: standard uptake or silly useless value? J Nucl Med. 1995; 36(10):1836-9.

45. Krak NC, Boellaard R, Hoekstra OS, Twisk JW, Hoekstra CJ, Lammertsma AA Effects of ROI definition and reconstruction method on quantitative outcome and applicability in a response monitoring trial. Eur J Nucl Med Mol I. 2005;32(3):294-301.

46. Nahmias C, Wahl LM. Reproducibility of standardized uptake value measurements determined by 18F-FDG PET in malignant tumors. J Nucl Med. 2008:49(11):1804-8.

47. Bai B, Bading J, Conti PS. Tumor quantification in clinical positron emission tomography. Theranostics. 2013;3(10):787-801.

48. Boellaard R. Standards for PET image acquisition and quantitative data analysis. J Nucl Med. 2009;50(Suppl 1):11s-20s.

49. Tomasi $G$, Turkheimer F, Aboagye E. Importance of quantification for the analysis of PET data in oncology: review of current methods and trends for the future. Mol Imaging Biol. 2012;14(2):131-46.

50. Houshmand S, Salavati A, Hess S, Werner TJ, Alavi A, Zaidi H. An update on novel quantitative techniques in the context of evolving whole-body PET imaging. PET Clin. 2015;10(1):45-58.

51. Boellaard R, Delgado-Bolton R, Oyen WJ, Giammarile F, Tatsch K, Eschner W, Verzijlbergen FJ, Barrington SF, Pike LC, Weber WA, et al. FDG PET/CT: EANM procedure guidelines for tumour imaging: version 2.0. Eur J Nucl Med Mol I. 2015;42(2):328-54.

\section{Ready to submit your research? Choose BMC and benefit from:}

- fast, convenient online submission

- thorough peer review by experienced researchers in your field

- rapid publication on acceptance

- support for research data, including large and complex data types

- gold Open Access which fosters wider collaboration and increased citations

- maximum visibility for your research: over $100 \mathrm{M}$ website views per year

At BMC, research is always in progress.

Learn more biomedcentral.com/submissions 